\title{
AGUA, SANEAMIENTO Y SALUD
}

\author{
WATER, SANITATION AND HEALTH
}

\author{
María del Carmen Gastañaga ${ }^{1, a}$
}

En muchas regiones del mundo el agua es un recurso cada vez más escaso ante el incremento demográfico y las consecuentes actividades domésticas, industriales, agrícolas, ganaderas, mineras, entre otras. Dicha situación ocasiona una gran demanda y genera la búsqueda de nuevas fuentes de abastecimiento; así el agua se torna en un valioso recurso que es necesario preservar para mantener un suministro permanente que asegure la vida en las ciudades.

En el caso del Perú, el servicio de agua y alcantarillado es todavía un serio problema; de acuerdo al Instituto Nacional de Estadística e Informática (INEI) en el periodo de febrero 2017 a enero 2018, el 10,6\% de la población total del país, no tuvo acceso a agua por red pública, es decir, se abastecen de agua de otras formas: camión/ cisterna $(1,2 \%)$, pozo $(2,0 \%)$, río/acequia/manantial $(4,0 \%)$ y otros $(3,3 \%){ }^{(1)}$. En el área urbana, el $5,6 \%$ de su población no tiene acceso a agua por red pública y consumen agua proveniente de camión cisterna $(1,3 \%$ de población), de pozo $(1,2 \%)$ y de río, acequia o manantial u otro $(3,2 \%)^{(1)}$. Por otro lado, el $28,1 \%$ de las personas del área rural no tienen acceso a agua por red pública, de los cuales en mayor porcentaje $(16,9 \%)$ acceden a agua de río, acequia o manantial, seguido de pozo $(5,1 \%)^{(1)}$.

El aumento de la demanda de agua trae consigo serios problemas de contaminación, tanto de naturaleza química como biológica, cuya corrección requiere de costosos sistemas de control. Al respecto, se calcula que las enfermedades diarreicas causan alrededor del $3,6 \%$ del total de los años de vida ajustados en función de la discapacidad debidos a enfermedades y causan 1,5 millones de fallecimientos cada año (2). De acuerdo con las estimaciones, el $58 \%$ de esa carga de enfermedad -es decir, 842000 muertes anuales- se debe a la ausencia de agua salubre y a un saneamiento y una higiene deficientes, e incluyen 361000 fallecimientos de niños menores de cinco años, la mayor parte de ellos en países de ingresos bajos ${ }^{(3)}$.

De otro lado, el proceso de desarrollo económico de los países trae consigo, en mayor o menor medida, la alteración de sus recursos naturales más valiosos como el agua, el aire y los suelos. Ejemplos nacionales lo constituyen la contaminación del río Rímac, la contaminación del lago Titicaca y otras fuentes de agua y lagunas a lo largo del territorio nacional. Grandes son los pasivos ambientales que tenemos al respecto, cuya solución es todo un reto para la investigación y del desarrollo tecnológico.

Un episodio notable de contaminación biológica de agua que marcó un hito en la historia de la salud pública es la que corresponde a la epidemia londinense de cólera en setiembre de 1854, en la que intervino el pionero de la epidemiología moderna, el Dr. John Snow, médico inglés que en su lucha contra el cólera puso en práctica sus observaciones, y hallazgos, encontrados en el registro de sus pacientes de cólera del sector Golden de la ciudad de Londres. Dicho sector era el foco de un brote de cólera de inusual intensidad que costó la vida de más de 500 personas en tan solo diez días. Snow sabía que la mayoría de los residentes del sector extraían el agua a partir de una bomba de uso público, por ello, planteó la hipótesis que el brote de cólera se debía a la ingestión de aguas contaminadas provenientes de esa bomba. El estudio de la bomba in situ demostró una conexión cruzada a menos de siete metros de profundidad de una tubería del alcantarillado que filtraba aguas servidas afectando toda el área de distribución de la bomba.

\footnotetext{
Centro Nacional de Salud Ocupacional y Proteccion del Ambiente para la Salud. Instituto Nacional de Salud. Lima, Peru.

Editora invitada; médico.

Recibido: 11/06/2018 Aprobado: 13/06/2018 En línea: 03/07/2018

Citar como: Gastañaga MC. Agua, saneamiento y salud. Rev Peru Med Exp Salud Publica. 2018;35(2):181-2. doi: 10.17843/rpmesp.2018.352.3732.
} 
La contribución de John Snow a la investigación epidemiológica es valiosa, y es un ejemplo de cómo la investigación científica puede contribuir al abordaje de problemas de salud pública incluyendo aquellos problemas de salud generados o transmitidos por el agua.

Dada la importancia del tema, la Revista Peruana de Medicina Experimental y Salud Pública presenta en este número una serie de publicaciones que abordan la temática del agua y salud. Se presentan tres artículos de simposio, el primero titulado "Reflexiones sobre la gestión de los recursos hídricos y la salud pública en el Perú » resalta el concepto de gobernanza hídrica como marco político e institucional para el desarrollo de la Gestión Integrada de los Recursos Hídricos (GIRH) ${ }^{(4)}$.

El concepto de gobernanza se focaliza en las formas y tipos de interrelación entre la sociedad civil y el Estado e inicia una serie de análisis sobre modelos y formas de gobernanza tomando en cuenta la estructura de las organizaciones (formal, informal, mixtas) y sus procesos. El segundo simposio «Calidad del agua y desarrollo sostenible», en el cual el autor menciona a la calidad del agua, como un valor ecológico esencial para la salud y para el crecimiento económico ${ }^{(5)}$. El manuscrito busca motivar a las autoridades sanitarias a desarrollar una evaluación más exhaustiva de las políticas de desarrollo en este sector para lograr beneficios sostenibles en el campo económico y sanitario.

$Y$ un tercero, «Enfermedades infecciosas relacionadas con el agua en el Perú», en donde se hace un revisión de como la carencia de agua segura y un adecuado saneamiento junto con el cambio climático y los desastres naturales pueden condicionar la permanencia de enfermedades relacionadas al agua como las diarreas, malaria, dengue, leptospirosis,

hepatitis virales $A$ y $E{ }^{(6)}$.

El número también incluye la investigación original «Concentraciones de Arsénico urinario en pobladores adultos de dos distritos de Candarave que consumen agua subterránea con arsénico», el cual muestra la magnitud de la exposición a aguas contaminadas con arsénico en poblaciones rurales del sur del Perú (7). Por último, en la carta al editor titulada «Concentración inadecuada de cloro residual libre en agua de hogares de Lima Metropolitana 2016», los autores presentan un análisis secundario de la Encuesta Nacional de Hogares (ENAHO) $2016{ }^{(8)}$, y encuentran una concentración inadecuada de cloro residual libre en un tercio de los hogares, finalmente recomiendan que se debe garantizar el derecho al acceso a agua segura para la disminución de enfermedades y mortalidad.

\section{REFERENCIAS BIBLIOGRÁFICAS}

1. Instituto Nacional de Estadística e Informática. Perú: Formas de Acceso al Agua y Saneamiento Básico [Internet]. Lima: INEI; 2018 [citado el 16 de junio de 2018]. Disponible en: https://www.inei. gob.pe/media/MenuRecursivo/boletines/boletin_agua_y_saneamiento.pdf

2. Organización Mundial de la Salud. Enfermedades y riesgos asociados a las deficiencias en los servicios de agua y saneamiento [Internet]. Ginebra: WHO; 2018 [citado el 16 de junio de 2018]. Disponible en: http://www.who.int/water sanitation health/diseases-risks/es/

3. Organización Mundial de la Salud. Agua [Internet]. Ginebra: WHO; 2018 [citado el 16 de junio de 2018]. Disponible en: http://www.who.int/es/news-room/factsheets/detail/drinking-water

4. Villena Chávez JA. Calidad del agua y desarrollo sostenible. Rev Peru Med Exp Salud Publica. 2018;35(2):304-8. doi: 10.17843/rpmesp.2018.352.3719.

5. Burstein-Roda T. Reflexiones sobre la gestión de los recursos hídricos y la salud pública en el Perú. Rev Peru Med Exp Salud Publica. 2018;35(2):297-303. doi: 10.17843/rpmesp.2018.352.3641.

6. Cabezas C. Enfermedades infecciosas relacionadas con el agua en el Perú. Rev Peru
Med Exp Salud Publica. 2018;35(2):309 16. doi: 10.17843/rpmesp.2018.352.3761.

7. Ale-Mauricio DA, Villa G, Gastañaga MC. Concentraciones de arsénico urinario en pobladores de dos distritos de la región Tacna, Perú, 2017. Rev Peru Med Exp Salud Publica. 2018;35(2):183-9. doi: 10.17843/rpmesp.2018.352.3693.

8. Bendezu-Quispe G, Whuking-Zea C, Medina-Molina P, Maruy-Yumi A, Namuche-Marín B. Concentración inadecuada de cloro residual libre en agua de hogares de Lima Metropolitana, 2016. Rev Peru Med Exp Salud Publica. 2018;35(2):347-8.doi:10.17843/rpmesp.2018.352.3648. 